\title{
Organizational and technological solutions justifying use of non-destructive methods of control when building monolithic constructions of civil buildings and structures
}

\author{
Azariy Lapidus, Alan Khubaev ${ }^{*}$ and Tembot Bidov \\ Moscow State University of Civil Engineering, Yaroslavskoe shosse, 26, Moscow, 129337, Russia
}

\begin{abstract}
The parameters influencing on the use of non-destructive methods of control are considered when building monolithic constructions of civil and industrial buildings and structures. The analysis of the factor influence on the capacity of the method of the non-destructive control with the expert assessment method is made. Based on the qualimetric analysis three the most significant groups of the factors which can influence on the capacity of the use of the non-destructive control method $\left(\mathrm{P}_{\mathrm{nc}}\right)$ are determined. The mathematical apparatus base is prepared, which characterize the object parameters.
\end{abstract}

\section{Introduction}

At present there is a big interest to the facilities and non-destructive control methods of the concrete strength due to the intensive construction development of the civil and industrial reinforce concrete buildings and structures and rising number of building destructions, caused by the poor control of its state. [1-4] When non-destructive control of the monolithic structure quality the development of the organizational and technological and management events are one of the key elements in the qualitative realization process of the construction object. There is a difficulty of the problem solution in the quality improving of the construction. This problem unites a set of the connected tasks, including the scientific and technical, economical and social ones. And effective problem solution of the quality improving of the construction should be complex. Moreover, the quality improving of the construction should be considered not as one-time event, but as a mandatory system in the overall daily work in all sectors of the construction production. But there are no regulations governing the use of the non-destructive control methods, considering all possible factors affecting the final high-quality products. [5-7] The mechanism of the organizational and technological operations plays a crucial role in making decisions on the use of the nondestructive control devices and the choice of their control method. [8,9] To date, there is no tool to assess the validity of the use of the non-destructive control methods in the construction of the monolithic reinforced concrete structures. Such a tool can be developed with the help of the organizational and technological solutions and the formation of such a

\footnotetext{
* Corresponding author: alan_khubaev@ mail.ru
} 
parameter as «Comprehensive index of the use capacity of the non-destructive control methods». $[10,11]$

\section{Main part}

A comprehensive index of the use capacity of the non-destructive control methods in the construction of the monolithic structures formed on the basis of the following factors [12]:

- $\quad$ Application of the non-destructive control methods (direct, indirect);

- $\quad$ Readiness of the construction site for testing;

- $\quad$ Presence of the information about the concrete;

- $\quad$ Project documentation quality;

- $\quad$ Seasonal check conditions;

To create the optimal conditions in order to determine the capacity of the nondestructive control, it is necessary to optimize all the above factors of the system and to obtain optimization groups. This requires consideration of all possible system states. The formula is used to determine:

$$
\mathrm{p}^{\mathrm{k}}=\mathrm{N}
$$

where $\mathrm{p}$ - the number of levels; $\mathrm{k}$ - number of the parameters; $\mathrm{N}$ - number of the experiments.

Given the fact that we have to lay for each of the five factors the possibility to vary at 3 levels, the full factorial experiment will take the form: $\mathrm{N}=3^{5}=243$, where 3 - the number of the variation levels, $\mathrm{N}=5-$ the number of the factors. Thus, to identify the desired dependence, we need 243 experiences. But for such a experiment number we need even more real objects, because if we take into account the confidence level $p=95 \%$, the value of the variation coefficient in the numerical index of the integral quality $\mathrm{C}_{\mathrm{v}}=5 \%$ and the test error $\varepsilon=5 \%$, the minimum number of the measurements for each line of the plan, with the student ratio $t=1.97$, will be:

$$
n=\frac{1,97^{2}+5^{2}}{5^{2}}=4
$$

To reduce the number of the experiments and ensure the independence of the parameters in the used mathematical model, we will correlate the parameters with the calculation of the coefficients of the pair correlation between all the possible pairs of the parameters - a common characteristic of the connection of two random variables in the mathematical statistics. To do this, we denote the parameters in the pair by $\mathrm{x} 1$ and $\mathrm{x} 2$ and number of experiments to measure them by $\mathrm{N}$, and the current number of the experience by $\mathrm{U}=1,2, \ldots$ , U. In this case, the formula is used to calculate the pair correlation coefficient $r$ :

$$
\mathrm{r}_{\mathrm{y}_{1} \mathrm{y}_{2}}=\frac{\sum_{\mathrm{u}=1}^{\mathrm{N}}\left(\mathrm{x}_{1 \mathrm{u}}-\overline{\mathrm{x}}_{1}\right)\left(\mathrm{x}_{2 \mathrm{u}}-\overline{\mathrm{x}}_{2}\right)}{\sqrt{\sum_{\mathrm{u}=1}^{\mathrm{N}}\left(\mathrm{x}_{1 \mathrm{u}}-\overline{\mathrm{x}}_{1}\right)^{2} \sum_{\mathrm{u}=1}^{\mathrm{N}}\left(\mathrm{x}_{2 \mathrm{u}}-\overline{\mathrm{x}}_{2}\right)^{2}}}
$$

Here:

$$
\begin{aligned}
& \overline{\mathrm{x}}_{1}=\frac{\sum_{\mathrm{u}=1}^{\mathrm{N}} \mathrm{x}_{1 \mathrm{u}}}{\mathrm{N}} \\
& \overline{\mathrm{x}}_{2}=\frac{\sum_{\mathrm{u}=1}^{\mathrm{N}} \mathrm{x}_{2 \mathrm{u}}}{\mathrm{N}}
\end{aligned}
$$

$\overline{\mathrm{x}}_{1}, \overline{\mathrm{x}}_{2}$ - arithmetic mean of the $\mathrm{x}_{1}, \mathrm{x}_{2}$ parameters;

Due to the fact that the studied parameters are defined as qualitative, to calculate each of them a numerical value must be assigned. To achieve these goals, we will use the method of expert assessments (table 1). 
First of all, we should define the designation parameters. Use: $x_{1}$ is the application of non-destructive control methods (direct, indirect); $x_{2}$ is the readiness of the construction site for the testing; $x_{3}-$ the presence of the information about the concrete; $x_{4}$-project documentation quality; $\mathrm{x}_{5}$ - seasonal conditions of the test.

The author compiled a questionnaire for the survey of experts who also participated in the preparation and formulation of the issue list. Experts were the authoritative, and they have a long-term professional experience of being heads of the construction structures working in the field of overhaul now. Ten expert groups with the scores ranging from 1 to 5 participated in the survey. Expert groups are designated as m1, m2,..., m10.

Table 1.

\begin{tabular}{|l|l|l|l|l|l|l|l|l|l|l|}
\hline & $\mathrm{m} 1$ & $\mathrm{~m} 2$ & $\mathrm{~m} 3$ & $\mathrm{~m} 4$ & $\mathrm{~m} 5$ & $\mathrm{~m} 6$ & $\mathrm{~m} 7$ & $\mathrm{~m} 8$ & $\mathrm{~m} 9$ & $\mathrm{~m} 10$ \\
\hline $\mathrm{x}_{1}$ & 4 & 5 & 4 & 3 & 4 & 3 & 3 & 4 & 5 & 3 \\
\hline $\mathrm{x}_{2}$ & 3 & 2 & 3 & 2 & 3 & 5 & 4 & 3 & 4 & 4 \\
\hline $\mathrm{x}_{3}$ & 5 & 4 & 5 & 5 & 5 & 4 & 5 & 5 & 3 & 5 \\
\hline $\mathrm{x}_{4}$ & 2 & 3 & 1 & 4 & 2 & 1 & 2 & 1 & 1 & 2 \\
\hline $\mathrm{x}_{5}$ & 1 & 1 & 2 & 1 & 1 & 2 & 1 & 2 & 2 & 1 \\
\hline
\end{tabular}

Almost all the experts unanimously preferred the availability of the concrete data as the main parameter determining the capacity of the non-destructive control methods.

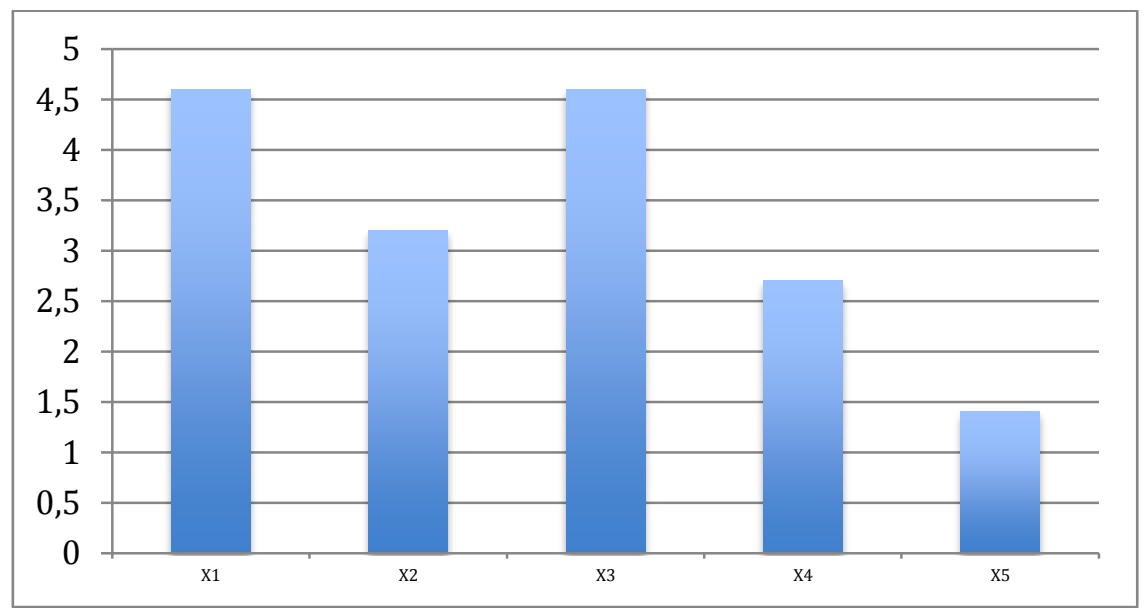

Fig. 1. Parameter histogram

To reveal the pair correlation coefficient (table 2 ) it is necessary to substitute statistical data from table 1 into formulas No. 2; 3 and 4. You can check the significance of the pair correlation coefficient by comparing its value with the table (critical) value. You also need to calculate the degree of the freedom using the formula:

$$
f=N-2
$$

where $\mathrm{N}$ is the number of the experiments on the measurement of the parameters or number of the expert groups;

In this case, if $f=8$ and the level of significance is 0.05 , the table value is $r_{c r}$. With the calculated $r>r_{c r}$ value we get a correlation linear bond: 
Table 2.

\begin{tabular}{|c|c|c|c|c|c|}
\hline & $x_{1}$ & $x_{2}$ & $x_{3}$ & $x_{4}$ & $x_{5}$ \\
\hline$x_{1}$ & 1.000 & -0.3111 & 0.187 & 0.878 & 0.386 \\
\hline$x_{2}$ & -0.3111 & 1.000 & 0.814 & -0.102 & -0.192 \\
\hline$x_{3}$ & -0.311 & 0.814 & 1.000 & 0.308 & -0.288 \\
\hline$x_{4}$ & 0.878 & -0.102 & 0.308 & 1.000 & 0.200 \\
\hline$x_{5}$ & 0.386 & -0.192 & -0.288 & 0.200 & 1.000 \\
\hline
\end{tabular}

Based on the obtained matrix, we can conclude that there is a very good correlation between the factors $x_{1}$ (application of non-destructive control methods) and $x_{4}$ (presence of non-destructive control devices). There is a very good correlation between factors $x_{3}$ (concrete information) and $x_{2}$ (quality of the project documentation). Factor $x_{5}$ (readiness of the construction site for the testing) is independent, as it is not correlated with other factors.

According to the results of the analysis, we can distinguish 3 groups of the well-related variables. The first group refers to non-destructive control tools and methods and includes factors $x_{1}$ and $x_{4}$. Let's call it $Z_{1}$. The second group characterizes the information component about the structural features of the structure, data on the composition of the concrete, the quality of the project documentation and the availability of the technological schemes of the testing. Includes $x_{2}$ and $x_{3}$ factors. Let's denote it $Z_{2}$. The third group is responsible for the readiness of the construction site for the testing and includes $x_{1}$ factor. Let's denote it $Z_{3}$.

\section{Conclusion}

As a result of the factor and dispersion analysis, three most significant groups of the factors that can affect the capacity of the non-destructive control of Pnc were identified. The first group refers to the choice of the methods of the non-destructive control in the construction of the monolithic structures, and is denoted by $Z_{1}$. The second group $Z_{2}$ is responsible for the quality of project documentation, the availability of the information about the concrete. The third group $\left(Z_{3}\right)$ is responsible for the measures to create an enabling environment for the testing.

Due to the done work, it is possible to create the optimal conditions for the future experiments. The obtained results are the basis for the creation of the mathematical apparatus, with which it is possible to fully characterize the object capabilities.

This work was financially supported by Ministry of Science and Higher Education of the Russian Federation (\#NSh-3492.2018.8).

\section{References}

1. A. Lapidus, T. Bidov, A. Khubaev, MATEC web of conferences, V. No. 00094, (DOI: 10.1051/matecconf/201711700094 (2017)

2. A. Goncharov, T. Bidov, G. Treskina, Scientific review, 12, 68-72 (2015)

3. A. Lapidus, T. Bidov, International Journal of Applied Engineering Research Volume 11, 8, 5972-5974 (2016)

4. A. Lapidus, I. Abramov, Science and Business: Development ways, 10 (2017) 
5. A. Lapidus, A. Makarov, Bulletin of Moscow State University of Civil Engineering, 8, 150-160 (2015)

6. A. Lapidus, A. Khubaev, Science and business: Development ways, 11(77), 7-11 (2017)

7. A. Lapidus, Vestnik MGSU, 1, 175-180 (2014)

8. A. Khubaev, Science prospects, 4 (103), 57-61 (2018)

9. R. Fatullaev, Components of Scientific and Technological Progress, 3 (33), 17-22 (2017)

10. T. Bidov, Scientific review, 13, pp. 54-57 (2017)

11. A. Khubaev, Science prospects, 4(103), 57-61 (2018)

12. A. Khubaev, T. Bidov, Science and business: Development ways, 4(82), 101-103 (2018) 